\title{
Control of breathing in hypercapnic patients with obstructive sleep apnoea
}

\section{To the Editor:}

We read with great interest the article by LiN [1] recently published in the Journal. The author described six patients with pure obstructive sleep apnoea (OSA), initially presenting with hypercapnia, which was resolved after 2 weeks of continuous positive airway pressure (CPAP) treatment.

It is well-known that hypercapnia is more frequent in patients with OSA and co-existing chronic obstructive pulmonary disease (COPD) than in patients with pure OSA [2-4]. Among 93 patients referred to our Sleep Laboratory, in whom the diagnosis of OSA was confirmed by full polysomnography, we found 22 subjects presenting, on admission, signs of hypercapnic respiratory failure. In 11 of these subjects, the diagnosis of COPD accompanying OSA was confirmed by typical history and spirometric findings [2]. They continued to present with elevated arterial carbon dioxide tension $\left(P \mathrm{a}, \mathrm{CO}_{2}\right)$ (sitting, awake) despite effective CPAP treatment.

Another 11 hypercapnic patients $(12 \%)$ were found to have pure OSA without chronic airway limitation. In seven subjects the responses of minute ventilation $\left(\Delta V^{\prime} E\right)$ and mouth occlusion pressure at $0.2 \mathrm{~s}$ after onset of inspiration $(\triangle P 0.2)$ to hypercapnic stimulus before CPAP, and arterial blood gas values before and on CPAP, were investigated. The patients were obese males (aged $45 \pm 8$ yrs, body mass index $49 \pm 8 \mathrm{~kg} \cdot \mathrm{m}^{-2}$ ) with severe OSA (apnoea+hypop-

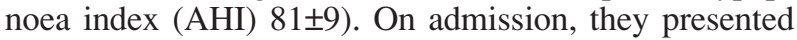
with signs of chronic respiratory failure (arterial oxygen tension $\left(\mathrm{Pa}, \mathrm{O}_{2}\right) 7.3 \pm 0.9 \mathrm{kPa}(55 \pm 7 \mathrm{mmHg}), \mathrm{Pa}_{2} \mathrm{CO}_{2} 6.7 \pm 0.4$ $\mathrm{kPa}(50 \pm 3 \mathrm{mmHg}))$ and normal spirometric results: vital

Table 1. - Ventilatory and mouth occlusion pressure responses to hypercapnia before CPAP treatment and arterial carbon dioxide tension before and on CPAP

\begin{tabular}{lcccc}
\hline $\begin{array}{l}\text { Subj. } \\
\text { No. }\end{array}$ & $\begin{array}{c}P \mathrm{a}, \mathrm{CO}_{2} \\
\text { before } \\
\mathrm{mmHg}\end{array}$ & $\begin{array}{c}P_{\mathrm{a}, \mathrm{CO}} \\
\text { on CPAP } \\
\mathrm{mmHg}\end{array}$ & $\begin{array}{c}\Delta V^{\prime} \mathrm{E} / \Delta P_{\mathrm{a}, \mathrm{CO}_{2}} \\
\mathrm{~L} \cdot \mathrm{min}^{-1} / \mathrm{mmHg}\end{array}$ & $\begin{array}{c}\Delta P 0.2 / \Delta P_{\mathrm{a}, \mathrm{CO}_{2}} \\
\mathrm{cmH}_{2} \mathrm{O} / \mathrm{mmHg}\end{array}$ \\
\hline 1 & 52.9 & 43.9 & 1.3 & 0.25 \\
2 & 50.0 & 40.0 & 1.6 & $0.21^{*}$ \\
3 & 46.8 & 40.7 & 1.7 & 0.30 \\
4 & 46.5 & 39.5 & 3.0 & 1.60 \\
5 & 50.7 & 40.8 & 3.1 & 0.78 \\
6 & 54.1 & 43.4 & 2.0 & 0.60 \\
7 & 46.0 & 40.9 & 2.2 & $0.19^{*}$ \\
\hline
\end{tabular}

*: $\Delta P_{0.1} ; \Delta V^{\prime} \mathrm{E} / \Delta P_{\mathrm{a}, \mathrm{CO}_{2}}:$ ventilatory response to hypercapnia, reference values $1.7-2.5 \mathrm{~L} \cdot \mathrm{min}^{-1} / \mathrm{mmHg} ; \Delta P 0.2 / \Delta P \mathrm{a}, \mathrm{CO}_{2}$ : mouth occlusion pressure response to hypercapnia, reference values $0.45-0.95 \mathrm{cmH}_{2} \mathrm{O} / \mathrm{mmHg}$. CPAP: continuous positive airway pressure; $P \mathrm{a}_{2} \mathrm{CO}_{2}$ : arterial carbon dioxide tension; $V^{\prime} \mathrm{E}$ : minute ventilation; $\Delta P 0.2$ : mouth occlusion pressure at $0.2 \mathrm{~s}$ after the onset of inspiration. $1 \mathrm{mmHg}=0.133 \mathrm{kPa}$. capacity (VC) $4.2 \pm 0.8 \mathrm{~L}$ ( $85 \pm 8 \%$ predicted), forced expiratory volume in one second $(\mathrm{FEV} 1) 3.2 \pm 0.6 \mathrm{~L}(83 \pm 5 \%$ pred), FEV1 as percentage of vital capacity (FEV1/VC) $76 \pm 2 \%$.

The results of $\Delta V^{\prime} \mathrm{E}, \Delta P 0.2$ and $P \mathrm{a}, \mathrm{CO}_{2}$ in each patient are presented in table 1. Only three patients had decreased $\Delta V^{\prime} \mathrm{E}$; others had $\Delta V^{\prime} \mathrm{E}$ slightly increased or within normal limits for our laboratory $\left(\Delta V^{\prime} \mathrm{E} / P \mathrm{a}_{1} \mathrm{CO}_{2} 2.1 \pm 0.4 \mathrm{~L} \cdot \mathrm{min}^{-1} / \mathrm{mmHg}\right)$ [2]. Four patients had decreased mouth occlusion pressure response to hypercapnia, two had $\triangle P 0.2$ within normal limits (predicted for our laboratory: $\triangle P 0.2 / P_{\mathrm{a}}, \mathrm{CO}_{2}$ $\left.0.7 \pm 0.25 \mathrm{cmH}_{2} \mathrm{O} / \mathrm{mmHg}[2]\right)$, and one had increased $\Delta P 0.2$.

Patients were given nasal CPAP treatment, which reduced AHI to $6 \pm 4$. After $7 \pm 3$ days of CPAP treatment, their daytime $P \mathrm{a}, \mathrm{O}_{2}$ increased to $8.1 \pm 1.1 \mathrm{kPa}(61 \pm 8 \mathrm{mmHg})$ $(\mathrm{p}<0.05)$ and $P \mathrm{a}, \mathrm{CO}_{2}$ decreased to normal level: $5.5 \pm 0.3$ $\mathrm{kPa}(41 \pm 2 \mathrm{mmHg})(\mathrm{p}<0.0001)$.

The number of hypercapnic OSA patients without coexisting chronic airway limitation reported in the literature is low. LEECH et al. [5] found 28 such patients among 111 consecutive apnoeics. Out of 114 OSA patients, KRIEGER et al. [3] found only four with chronic daytime hypercapnia and FEV1/FVC more than $65 \%$. In the study reported by CHAOUAT et al. [4], hypercapnia was present in $8 \%$ of 235 pure OSA patients.

The results of hypercapnic ventilatory response in OSA patients with hypercapnia are not uniform. Some authors [6, 7], like LiN [1], found all their patients to have decreased $\Delta V^{\prime} \mathrm{E}$ and mouth occlusion pressure at $0.1 \mathrm{~s}$ after onset of inspiration $(\triangle P 0.1)$ responses to hypercapnia and to hypoxia. However, Kunitomo et al. [8] reported that out of four OSA patients with hypercapnia and normal spirometric values, two had decreased $\Delta V^{\prime} E$ response both to hypercapnia and hypoxia; one of them had decreased $\triangle P 0.2$ response to hypoxia, and the other had decreased $\triangle P 0.2$ response to hypercapnia. A third patient had decreased $\Delta P 0.2$ response to hypercapnia only; and the last had normal results for all $\Delta V^{\prime} \mathrm{E}$ and $\Delta P_{0.2}$ responses.

Thus, in conclusion, most reported hypercapnic OSA patients without co-existing COPD have decreased hypercapnic and hypoxic ventilatory responses. However, some published data and our own observations suggest that there are some patients with pure OSA and daytime hypercapnia who have normal or even augmented ventilatory responses to hypercapnic and hypoxic stimuli.

Returning to the study by LIN [1], it seems to us that the units of $\Delta V^{\prime} \mathrm{E}$ and $\Delta P 0.1$ responses to hypercapnia in their table 2, 6th and 8 th line $\left(\mathrm{L} \cdot \mathrm{min}^{-1} / \mathrm{kPa}\right.$ and $\mathrm{cmH}_{2} \mathrm{O} / \mathrm{kPa}$, respectively) do not correspond to reported values. The mean results of the tests shown in the table seem to be calculated in $\mathrm{L} \cdot \mathrm{min}^{-1} / \mathrm{mmHg}$ and $\mathrm{cmH}_{2} \mathrm{O} / \mathrm{mmHg}$, respectively. 


\section{References}

1. Lin C-C. Effects of nasal CPAP on ventilatory drive in normocapnic and hypercapnic patients with obstructive sleep apnoea syndrome. Eur Respir J 1994; 7: 2005-2010.

2. Radwan L, Maszczyk Z, Koziorowski A, et al. Control of breathing in obstructive sleep apnoea and in patients with the overlap syndrome. Eur Respir J 1995; 8: 542-545.

3. Krieger J, Sforza E, Apprill M, Lampert E, Wietzenblum E, Ratomaharo J. Pulmonary hypertension, hypoxemia and hypercapnia in obstructive sleep apnea patients. Chest 1989; 96: 729-737.

4. Chaouat A, Weitzenblum E, Krieger J, Ifoundza T, Oswald M, Kessler R. Association of chronic obstructive pulmonary disease and sleep apnea syndrome. Am J Respir Crit Care Med 1995; 151: 82-86.

5. Leech JA, Önal E, Baer P, Lopata M. Determinants of hypercapnia in occlusive sleep apnea syndrome. Chest 1987; 92: 807-813.
6. Garay SM, Rapaport D, Sorkin B, Epstein H, Feinberg I, Goldring RM. Regulation of ventilation in obstructive sleep apnea syndrome. Am Rev Respir Dis 1981; 124: 451-457.

7. Verbraecken J, Willemen M, Wittesaele W, De Cock W, Van De Heyning P, De Backer W. Chronic $\mathrm{CO}_{2}$ drive in patients with obstructive sleep apnea, heavy snoring and healthy controls. Chest 1993; 103 (Suppl. 3): 321S.

8. Kunitomo F, Kimura H, Tatsumi K, et al. Abnormal breathing during sleep and chemical control of breathing during wakefulness in patients with sleep apnea syndrome. Am Rev Respir Dis 1989; 139: 164-169.

\section{Koziej*, J. Zielinski, L. Radwan}

Dept of Respiratory Medicine, and Lung Function Laboratory, Institute of Tuberculosis and Lung Diseases, Warsaw, Poland.

*Supported by The 1995 Young Investigators Research Grant awarded by The Foundation for Polish Science.

\section{REPLY}

\section{From the author:}

Thank you for your letter and for your interest in my paper entitled "Effect of nasal CPAP on ventilatory drive in normocapnic and hypercapnic patients with obstructive sleep apnoea syndrome". I must apologize for a typographical error in the units for $\Delta V^{\prime} \mathrm{E}$ and $\Delta P_{0.1}$ response to hypercapnia in table 2 , lines 6 and 8 . They should be $\mathrm{L} \cdot \mathrm{min}^{-1} / \mathrm{mmHg}$ and $\mathrm{cmH}_{2} \mathrm{O} / \mathrm{mmHg}$ (table 2). Thank you for drawing my attention to this misprint.

I also agree that, even though most reports, as well as our results, suggest that hypercapnic obstructive sleep apnoea (OSA) patients without co-existing COPD have decreased hypercapnic and hypoxic ventilatory responses [1-4], some published data, including your observations, suggest that there are some patients with pure OSA and daytime hypercapnia who have normal or even augmented ventilatory response to hypercapnic and hypoxic stimuli [5]. One possible reason for the discrepancy between our results and yours is that our patients had a more restrictive defect ( $\mathrm{FVC}=70 \pm 3.8 \%$ predicted). In contrast, your subjects had normal lung function ( $\mathrm{VC}=85 \pm 8 \%$ predicted). These varying responses suggest, as we proposed in our paper, the need for further prospective studies with larger numbers of subjects. Thank you for your attention.

\section{References}

1. Aubert-Tulkens G, Willems B, Veriter CL, Coche E, Stanescu DC. Increase in ventilatory response to $\mathrm{CO}_{2}$ following tracheostomy in obstructive sleep apnea. Bull Eur Physiopathol Respir 1980; 16: 587-593.

2. Guilleminault C, Cummiskey J. Progressive improvement of apnea index and ventilatory response to $\mathrm{CO}_{2}$ after tracheostomy in obstructive sleep apnea syndrome. Am Rev Respir Dis 1982; 126: 14-20.

3. Berthon-Jones N, Sullivan CE. Time-course of change in ventilatory response to $\mathrm{CO}_{2}$ with long-term CPAP therapy for obstructive sleep apnea. Am Rev Respir Dis 1987; 135: $144-147$.

4. Lin CC. Effects of nasal CPAP on ventilatory drive in normocapnic and hypercapnic patients with obstructive sleep apnoea syndrome. Eur Respir J 1994; 7: 2005-2010.

5. Radwan L, Maszczyk Z, Koziorowski A, et al. Control of breathing in obstructive sleep apnoea and in patients with the overlap syndrome. Eur Respir J 1995; 8: 542-545.

\section{C-C. Lin}

Mackay Memorial Hospital, 92, Sec. 2, Chung San N. Road, Taipei, Taiwan. 